\title{
Microwave Drilling with Litz Wire using a Domestic Applicator
}

\author{
Nitin K. Lautre, Apurbba K. Sharma, Pradeep Kumar and Shantanu Das
}

\begin{abstract}
The work presented in the paper shows a way to drill a blind hole on perspex material at $2.45 \mathrm{GHz}$ frequency of microwaves using a domestic applicator of 700 $W$ maximum powers. The approach was based on the approach was based on the application of a Litz wire coax as a monopole, to act like a drill bit with a heat source. The methodology involves no rotary but, single linear movement of tool inside a microwave applicator for drilling. A computer simulation on COMSOL for about 50 minute each run, was also used to show the heat distribution inside microwave applicator. The result of computer simulation helped to locate the optimized position of Litz wire inside the applicator for optimum heat generation. The experimental results show the feasibility of microwave drilling and limitations on perspex specimen in the used applicator. The work presented involves a new approach in the area of microwave drilling of materials on a customized domestic microwave setup.
\end{abstract}

Keywords--- Applicator, COMSOL, Drilling, Litz, Microwave, Perspex

\section{INTRODUCTION}

$\mathrm{M}$ CROWAVE energy and drilling process are two different popular areas in the field of engineering. Microwave concepts are relatively newer to that of drilling. Many of the researchers have tried to overcome the limitation of traditional drilling process with the newer emerging concepts. Microwave drilling is one such approach presented in the year 2000 [1]. The importances of some of applications in the area of microwave material processing are rising in terms of their popularity and consequently researched [2]. The active research areas include microwave assisted sintering, material interaction, modeling, equipment and its design, measurements, etc. Most of the research works in microwave assisted material processing however are limited to processing of ceramics followed by composites.

Nitin K. Lautre, Research Scholar, Department of Mechanical and Industrial Engineering, Indian Institute of Technology, Roorkee, India. Email:nfl_123@rediffmail.com

Dr. Apurbba K. Sharma, Associate Professor, Department of Mechanical and Industrial Engineering, Indian Institute of Technology, Roorkee, India. Email:akshafme@gmail.com

Dr. Pradeep Kumar, Professor, Department of Mechanical and Industrial Engineering, Indian Institute of Technology, Roorkee, India. Email:kumarfme@gmail.com

Shantanu Das, Scientist - H, Reactor and Control Division, Bhabha Atomic Research Center, Mumbai, India. Email:shantanu@magnum.barc.gov.in

DOI: 10.9756/BIJIEMS.6053
Majority of the work reported was confined to metallurgical processing of material. However, microwave assisted mechanical processes received very less attention. Some of the developments in the areas of application of microwaves for various processes like sintering, cladding, melting, coating, glazing, joining, cladding and co-axial cable assisted drilling, etc. are reported [3] - [8]. The area of microwave drilling on various materials like concrete, glass, ceramics, basalts, silicon, and bones are well envisaged and explored [9] - [12]. The application of bone drilling in biomedical engineering, electronics industry and aeronautical engineering involves the majority of recent drilling applications for small size holes [13] - [18].

Researchers have tried to drill hole in perspex of $2.5 \mathrm{~mm}$ thick through a $1064 \mathrm{~nm}$ diode laser. The power of $1 \mathrm{~W}$ without decrease in pressure and $2.45 \mathrm{~W}$ at a low pressure of $60 \mathrm{~mm} \mathrm{Hg}$ of air was used to drill a hole [19]. A careful control of various parameters like the preparation of precise nozzle diameter, its focal point, lens effect, speed of cut, cutting power, standoff distance, hole circularity, spatter thickness, material removal rate and assists gas pressure adjustment add complexity. These controls hinder the drilling process for attaining a high aspect ratio holes with low taper ratio [20] - [22]. An attempt is made to use different wavelength the degrade perspex to cause burning, cracking, boiling in and around the imposed laser part and nearby. The wavelength varied from near infrared $(1064 \mathrm{~nm})$ to visible $(532 \mathrm{~nm})$ to ultraviolet $(266 \mathrm{~nm})$ wavelength. At $266 \mathrm{~nm}$ the photo chemical dissociation by covalent bond breaking (photo-ablation) was more dominating than thermal ablation in perspex [23] - [24]. A high aspect ratio of 300- 600 for hole ranging from $10-100$ micron is reported [25] - [26]. For blind holes a surface modification is prepared by exposing perspex to laser beam. The thermochemical damages due to carbonization of perspex into small spots are reported [27] [28]. Conventionally the drilling of perspex establishes the significant parameter to be controlled for effective drilled hole as the speed, feed rate, thrust force, tool wear, delamination [29] - [30] and hole shrinkage. A high speed steel drill bit is related significantly with power and acoustic emission. The acoustic emission is unavoidable and is due to assembly of mechanically vibrating and rotating system [31]]. Microwave drilling makes an attempt to minimize the problem observed in conventional and non conventional (laser) drilling process.

It has been found that very few researchers are active in the domain of microwave drilling at present. The behavior of microwave drilling in a closed applicator is infact, highly complex as it is governed by various phenomena. Concepts like dielectric behavior of material in high temperature, hot spot formation, thermal runaway as well as safety 
considerations usually dominate the developments in the field. Each concept plays a very important role and mostly depends on the material properties of specimen, drill bit and ambient conditions.

The current paper highlights on the process of microwave drilling on perspex (PMMA: Poly Methyl Methaacrylate) with monopole (half dipole) coax drill bit. It also highlights the arrangement of domestic microwave applicator for the process of microwave drilling. An attempt is also made to simulate the heat distribution required for microwave drilling in the customized microwave applicator.

\section{EXPERIMENTAL SETUP AND CUSTOMIZATION}

A microwave applicator (make: Haier, model: HR-1770 $\mathrm{M}$ ) as shown in figure 1, was used for the drilling trials. It is basically designed for domestic application of cooking food items. It was thus further modified by drilling a hole of $12 \mathrm{~mm}$ at the top roof. For unbiased heat distribution, the hole was drilled at the middle of the top face of the applicator. The maximum power level of the applicator was $700 \mathrm{~W}$ which can be applied in four steps. The maximum susceptible time inside the microwave applicator was 3 minute in a step of 1 minute.

A top plate of galvanized steel with a cylindrical waveguide of internal diameter $12 \mathrm{~mm}$ was used to cover the top face of the applicator. The customized arrangement of this cylindrical wave guide also helps to facilitate the entry of the coax as drill bit. The customized microwave applicator with coax was shown in figure 2. Since the outer diameter of dielectric of coax was of $\Phi 7.3 \mathrm{~mm}$, the outer copper straps surrounding dielectric were restricted by the cylindrical waveguide. This facilitates the coax to act as a monopole tool inside the applicator.

Most of the time for effective resonance the length of coax entering the applicator was kept at quarter wavelength $(\lambda / 4 \sim$ $30.5 \mathrm{~mm}$ ) of $2.45 \mathrm{GHz}$ microwave. The entered monopole coax was not directly connected to microwave source magnetron. The incident microwave reflections in all direction are constrained and only the reflection perpendicular to the axis of the coax was used. The base rotary disc was removed in order to have more concentrated heat on the target material rather than distributed heating. The drill bit was placed inside the applicator in proximity to the specimen through the circular wave guide manually. The specimen was supported with a platform of microwave absorbing brick. These refractory brick acts as the work piece supporting platform and do not involve in heat transfer.

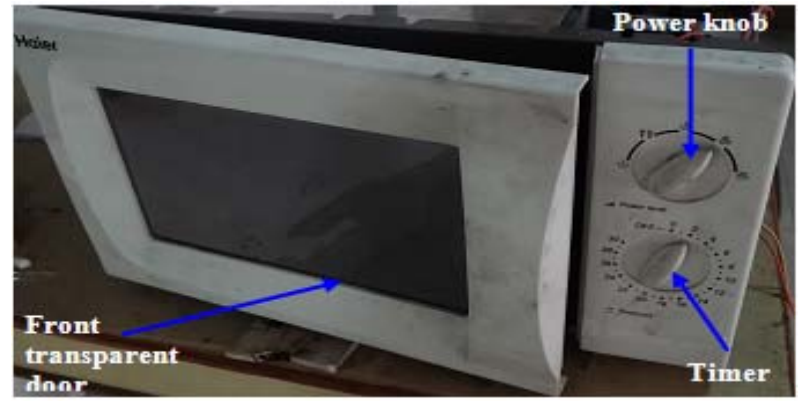

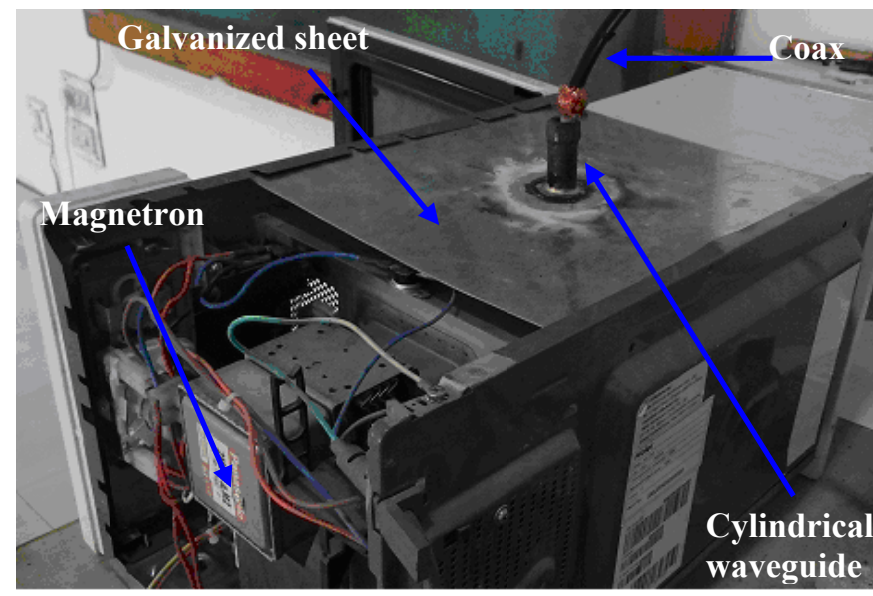

Figure 2: Customized Microwave Applicator with Coax Cable

The materials used in the customized applicator are basically of two types: the tool as microwave reflective material and the specimen as microwave transparent material. Microwave reflective material while reflecting the incident radiation allows microwave to penetrate upto its skin depth and generates spark. The spark generation was due to the voltage build up and sudden breaking of the insulating air film at the periphery of reflective material. Both the characteristic of reflective material was helpful in concentrating the microwave energy through thermal runaway process. On the other hand the microwave transparent material does not interact with microwave and usually have lower melting point as compared to the reflective material.

A piece (12.5 X 11 X $5 \mathrm{~mm}$ : L X B X H) of perspex was selected as workpiece. It has a melting point of about $160{ }^{\circ} \mathrm{C}$, weight density as $1.18 \mathrm{~g} / \mathrm{cm}^{3}$ and chemical formula as of $\left(\mathrm{C}_{5} \mathrm{O}_{2} \mathrm{H}_{8}\right)_{\mathrm{n}}$. A typical workpiece specimen is shown in figure 3 .

Perspex has wide application in aerospace and automobile industry. It has superseded glass in many applications owing to its light weight, durability and less brittleness. In assembly of PMMA mechanical drilling plays an important role and needs to be accelerated in mass production. A typical EDS (Energy Dispersive Spectroscopy) spectrum of the work specimens is shown in figure 4 . The chemical composition as recorded by the spectrum percentage of carbon and oxygen was $65.16 \%$ and $34.84 \%$ correspondingly.

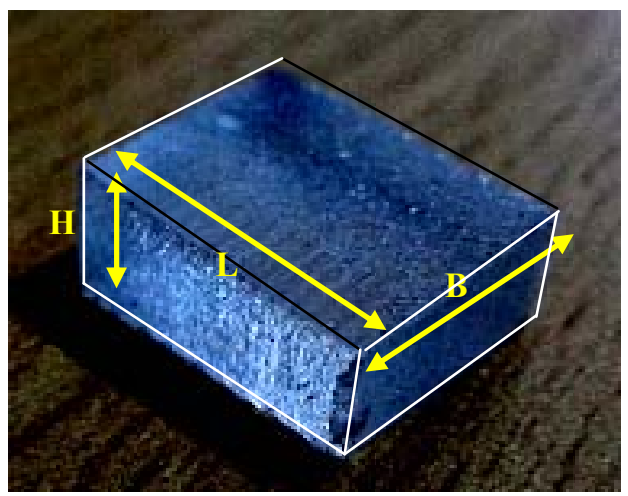

Figure 3: PMMA Work Piece Specimen

Figure 1: Microwave Basic Applicator 


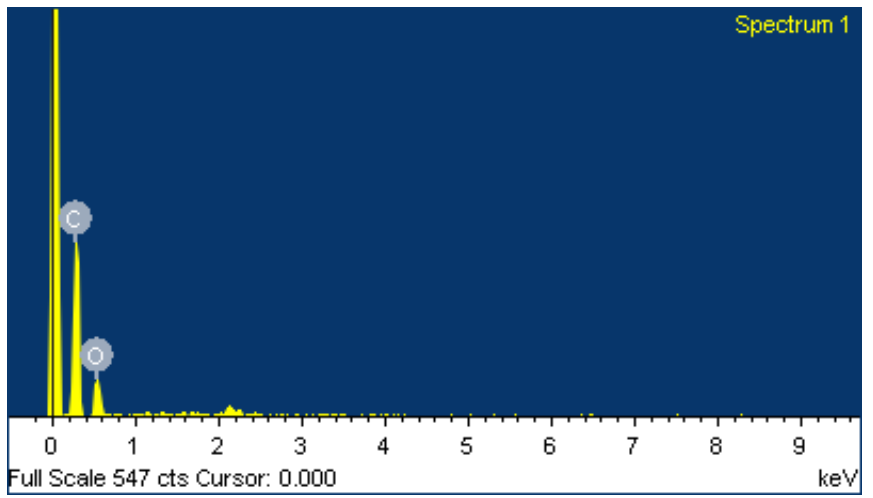

Figure 4: EDS Spectrum of PMMA Specimen

The drill bit chosen for the experimentation was a coax cable with twisted strands of copper wire commonly known as Litz wire as shown in figure 5(a). These wires are commonly used for carrying $\mathrm{AC}$ (Alternating Current) at low frequency upto $1 \mathrm{MHz}$. It has a group of seven copper wire strands each of diameter $\Phi 0.6 \mathrm{~mm}$. After winding of these individual wires, the diameter of the drill bit tool was maintained at $\Phi 2.1$ $\mathrm{mm}$.

The diameter of individual wire was so selected to reduce the skin effect as its effectiveness increases if wire diameter is less than the twice the skin depth. For copper at $2.45 \mathrm{GHz}$, the skin depth is $1.35 \mu \mathrm{m}$. A copper wire of $2.7 \mu \mathrm{m}$ will be very thin and less stiff to act as a drill bit. The Litz wire used was of Suhner make, RG 213/U, $50 \mathrm{ohm}$ as shown in figure 5(b). The bunch of wounded wire of $\Phi 2.1 \mathrm{~mm}$ was surrounded by a dielectric material shield of $\Phi 7.3 \mathrm{~mm}$. This diameter $(\Phi 7.3$ $\mathrm{mm}$ ) was less than the top hole drilled $\Phi 12 \mathrm{~mm}$, which allows the monopole of group of wire to enter along with dielectric cover inside the applicator. The dielectric cover was further surrounded by criss cross woven thin copper straps as shown in figure 5(a), which are finally covered by a protective plastic cover.
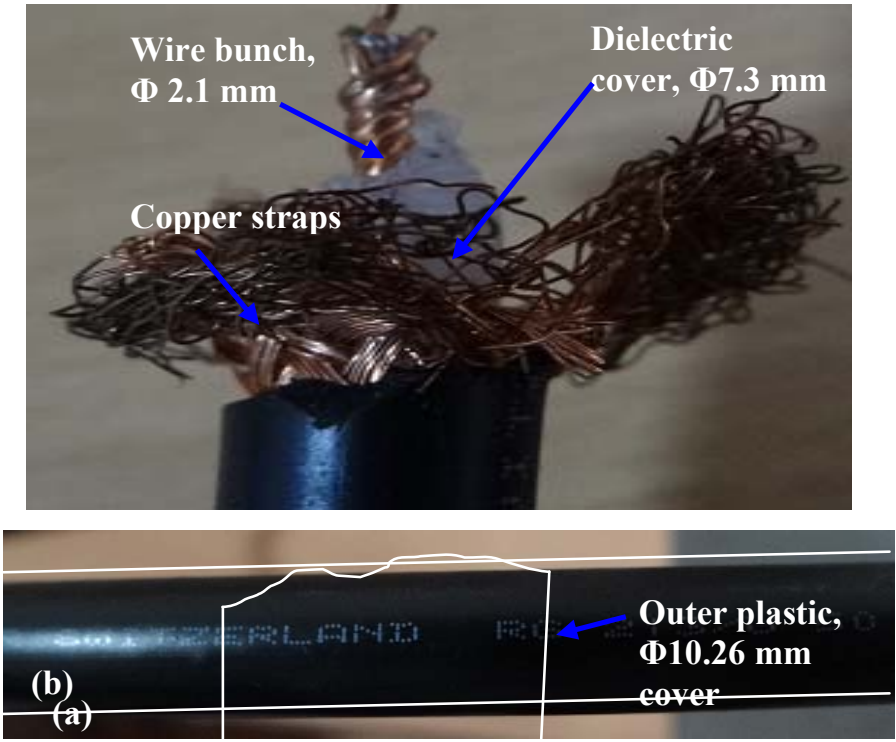

Figure 5: (a) Coax litz wire (b) Specification on Coax Cable

The criss cross or basket weaved copper straps donot keep two straps or wire parallel to each other causing cancellation of wire magnetic field between successive twists. Also, at higher frequencies more and more signals are transferred in the outermost layer of the coax becomes effective. The final outer diameter after the plastic cover for the coax was $\Phi 10.26$ $\mathrm{mm}$. Since the arrangement was of monopole entry the copper straps are spread to increase the overall diameter beyond 12 $\mathrm{mm}$ to restrict the entry of copper strap and outer protective cover inside the applicator.

The cross section of the Litz wire has typically arranged wire relative to each other as shown in figure 6 . The wire is wound in such a way that they form a hexagonal honeycomb shape grid with central wire inside the grid. This arrangement has the capability to induce eddy current on the nearby wire, and hence improves the current flow over the Litz wire. Since the wire cross sections is circular and twisted over each other and are equally spaced wire, it leads to six void patches as shown in figure 6 . These voids are acting as insulator and are unavoidable.

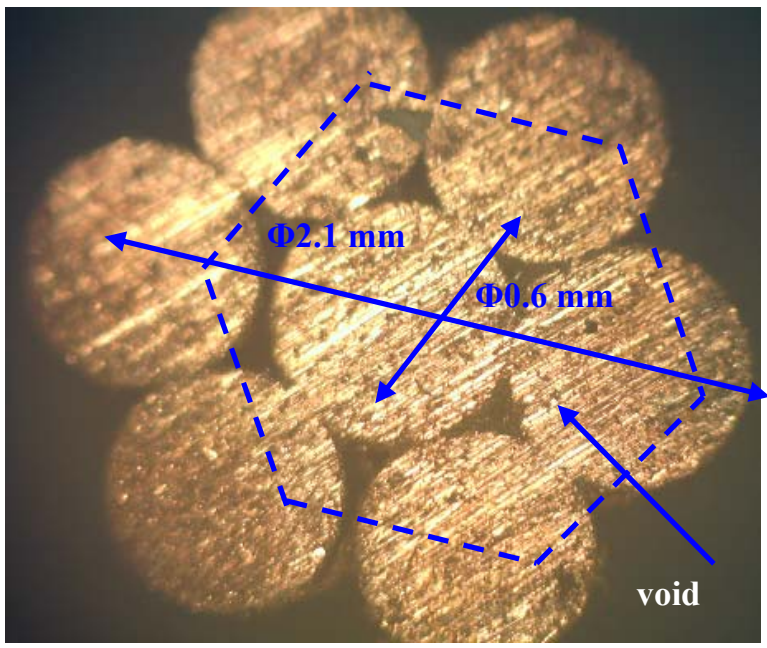

Figure 6: Cross section of Litz wire

\section{COMSOL SIMULATION}

The experimentation for microwave irradiation requires an idea of the temperature distribution inside the applicator without the presence of stirrer and rotary plate. A simulation tool (COMSOL of 4.3 version 0.151 ) was used to simulate the temperature profile for effectively positioning the workpiece and drill bit in the applicator. The geometrical model with exact size of the microwave cavity is shown in figure 7 . The dimensions of the applicator used are 285 X 277 X 182 (L X B $\mathrm{X} \mathrm{H}) \mathrm{mm}$. The grids of predrilled hole on either side of vertical face was ignored in simulation, as theses holes are to release the gases trapped in the cavity through forced convection. 


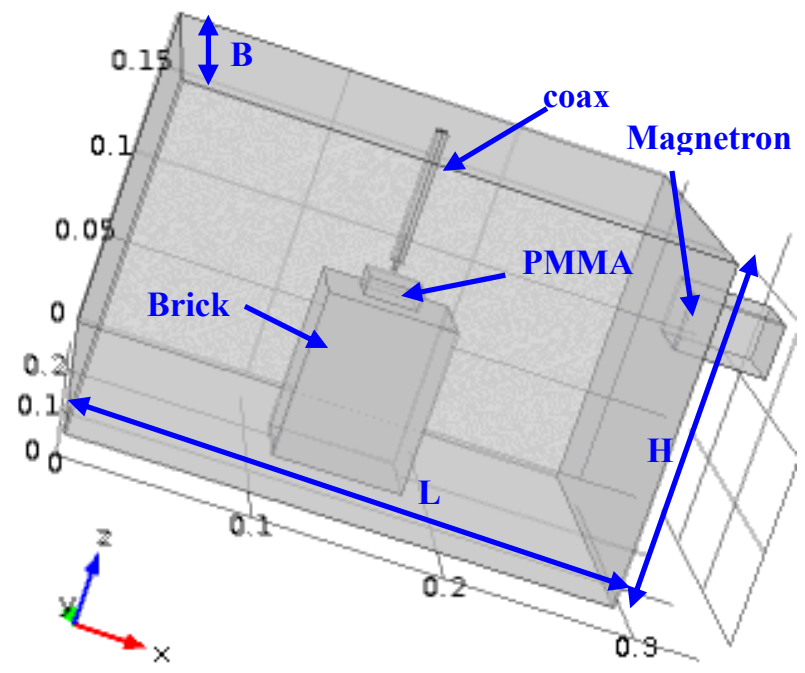

Figure 7: Geometrical Model of the Experimental Setup

A frequency transient study was performed at power rating of $700 \mathrm{~W}$ with power application cycle time of less than 3 minute. In order to estimate the variation of heat in the applicator, a series of simulation runs were performed for microwave heating. Each run inside the microwave oven module was iterating and converging for a cycle time of about 50 minute. The other parameters selected during simulation were model definition of air, no heat transfer, port boundary, meet boundaries to respective domains.

The variation of electric field and resistive losses as obtained through simulation are shown in figure 8(a). It is clear from the figure that throughout the irradiation trial, the tool and the workpiece will be within the safe limit and the heat variations are cyclic. It was also seen that the higher heating envelope was away from the center of the applicator. As pointed out, the temperature distributions are more uniform away from the center axis of the cavity [32]. The overheating of the coax was thus not possible for low exposure time (30 s). The resistive heating in $\mathrm{W} / \mathrm{m}^{3}$ was more around the brick as shown in figure $8(\mathrm{~b})$. The smaller size of specimen also helps the working atmosphere to be maintained at lower initial temperature variation without interfering the resistive heating area.

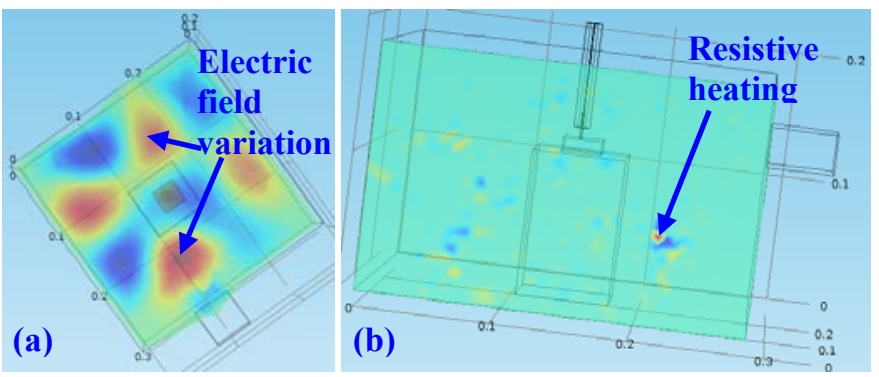

Figure 8: Variation in (a) Electric Field and (b) Resistive Losses in Microwave Applicator

In order to find out the optimum coordinates for effective microwave heating inside the applicator, Table 1 has been constructed from the simulation results. The temperature variation of three times the melting point of PMMA was assumed from the center to around the brick. It is concluded from the data that for the application of less than $480{ }^{\circ} \mathrm{C}(\sim$ $160 * 3$ times) temperature near the drilling zone, the ideal location for the drill bit will be about the center, as it will not interfere the high electric field generated around the brick area.

Since the top face drilled hole may not permit any $x-y$ change; the data of z-axis along the drill bit height was effective. The $\mathrm{z}$ axis data help to allow a particular length of coax inside the applicator for optimized heat concentration for drilling. The optimum entry distance for the drill bit was $\mathrm{H}$ $142 \mathrm{~mm}=40 \mathrm{~mm}$ as shown in figure 9. The condition of Litz wire become sensitive, if the entry distance of about $40 \mathrm{~mm}$ was not maintained. A burnout was observed due to sudden rise in temperature at coax in 2 minute, as shown in figure 10. The burnout had not only burnt the start portion of drill bit but, also melted the dielectric cover over it. This clears the temperature range generated at drill bit end in the microwave applicator. A need of research for good and tolerable dielectric cover to withstand such elevated temperature is considerable to prevent the dielectric cover burn outs.

Table 1: Variation of Temperature with Coordinated of Applicator

\begin{tabular}{|c|c|c|c|}
\hline $\mathrm{x}$ & $\mathrm{y}$ & $\mathrm{z}$ & $\operatorname{Temp}\left({ }^{\mathrm{O}} \mathrm{C}\right)$ \\
\hline 0.1079 & 0.1472 & 0.14146 & 438.1342 \\
\hline 0.09441 & 0.09193 & 0.14214 & 643.2254 \\
\hline 0.25801 & 0.1199 & 0.14247 & 741.0294 \\
\hline 0.255 & 0.11098 & 0.14276 & 827.4488 \\
\hline 0.06919 & 0.053 & 0.14277 & 832.0689 \\
\hline 0.08321 & 0.13952 & 0.14283 & 850.6143 \\
\hline 0.08078 & 0.06883 & 0.14285 & 856.7601 \\
\hline
\end{tabular}

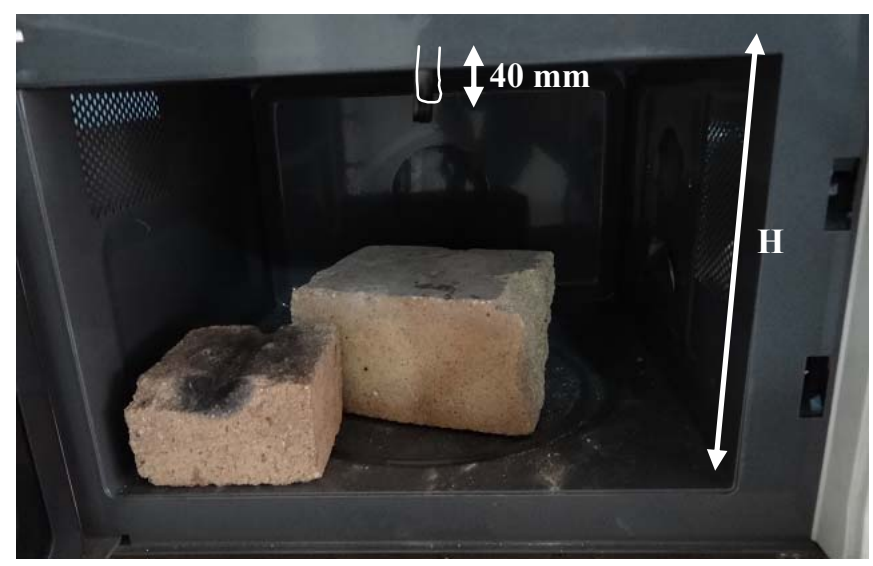

Figure 9: Optimized Entry of the Drill Bit from Top

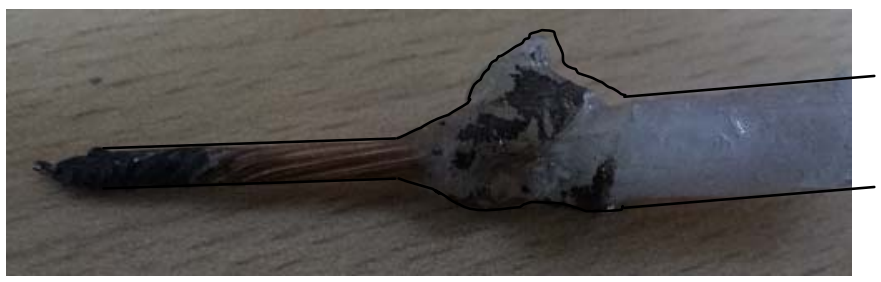

Figure 10: Burnt Litz Wire 


\section{RESULTS AND DISCUSSION}

The trials were performed as per the simulated parameters to drill a blind hole. The experimentation was performed with simple setup and does not involved complex waveguide and motorized stirrer and circulating motor. Prior to starting the trials the workpiece platform was adjusted to the optimized height obtained through simulation. The PMMA workpiece was placed above the brick and beneath the circular wave guide. The Litz wire was then inserted in the circular waveguide with inner core as monopole. The axial movement of the Litz wire was manually controlled. It was observed that for an average time of about 2 to 3 minute at $700 \mathrm{~W}$ maximum power, a blind hole was drilled on PMMA specimen as shown in figure 11.
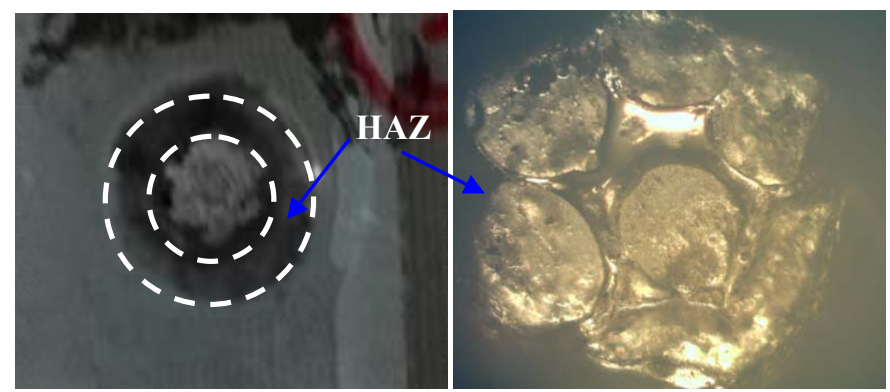

Figure 11: Drilled Hole on PMMA Specimen with Litz Wire

It was observed that the hole was exact replica of the cross section of the Litz wire (figure 6). In addition to the hole a heat affected zone (HAZ) around the hole was also observed. At higher magnification the HAZ are shown in figure 12; the observed HAZ was measured to about $0.8 \mathrm{~mm}$ thick. The area between the hole and the HAZ was generally occupied by the porous material, which gets evacuated by microwave heating and penetration of drill into PMMA specimen. The depth of penetration of coax in PMMA specimen was measured and observed to be $3 \mathrm{~mm}$ of blind hole as shown in figure 13 .

A scanning electron Microscope (SEM) image obtained for the drilled PMMA specimen is shown in figure 14. The trace mark of the cross section of Litz wire was easily visible in the image. The evacuated porous material due to drill penetration in PMMA under hot condition was also seen. The porous material coming out from the specimen may be having less viscosity to flow at the top surface with siphon action at the boundaries of the Litz wire and the wall of the drilled hole. The drill does not have any cavity or gap to direct the porous material to a particular direction.

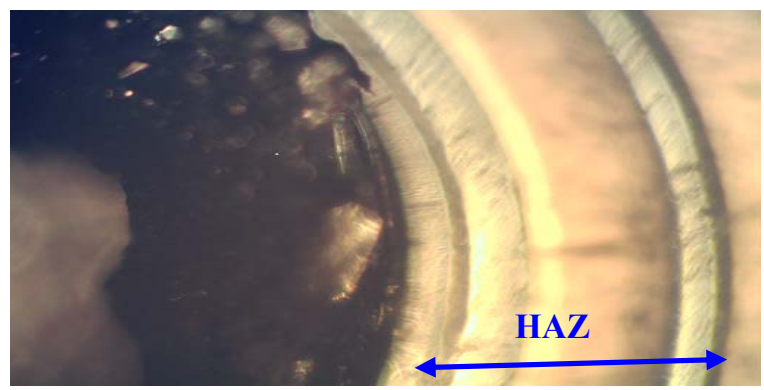

Figure 12: HAZ on PMMA Specimen

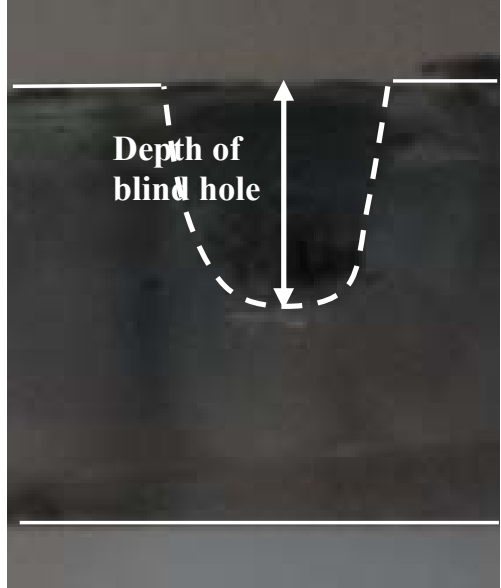

Figure 13: Penetration Depth of Drill Bit

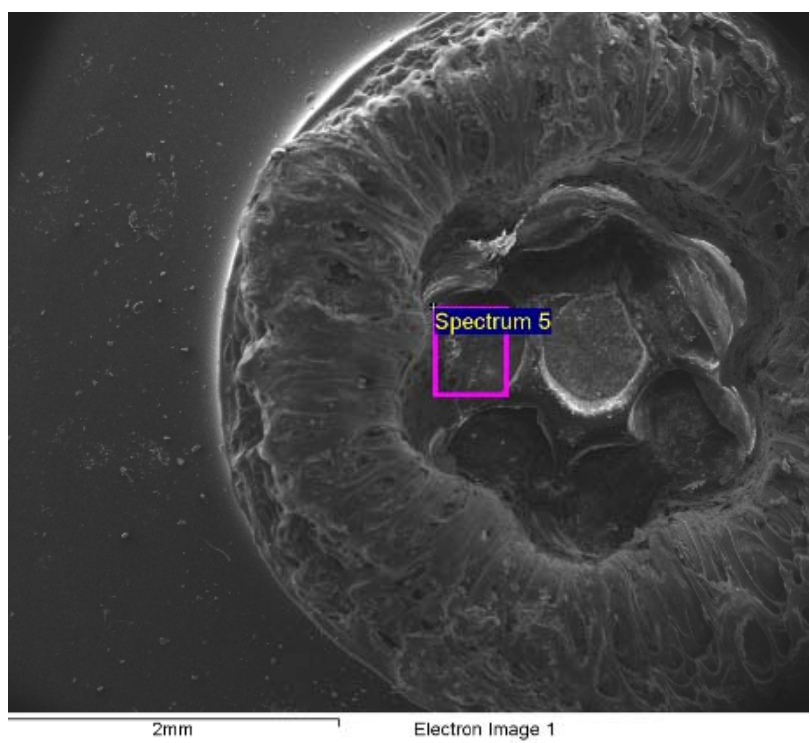

Figure 14: SEM Image of Drilled Hole on PMMA Specimen

The EDS spectral analysis of the bottom surface of the blind hole were also attempted as shown in figure 15. It was observed that the composition of the PMMA got marginally changed (reference: figure 4) after the microwave drilling process. The weight percentages of carbon and oxygen were found to be $59.3 \%$ and $19.06 \%$. The change is indicative of chemical changes at higher temperature during melting and evaporation. In addition to these a small traces of copper and zinc were observed with weight percentage of $9.77 \%$ and $11.87 \%$ with atomic percentage of $2.38 \%$ and $2.81 \%$ respectively. This clears the fact that during the microwave drilling process tool (Litz wire) has also experienced wear. The particle lost by the tool was further accumulated on the blind end of the work piece; further analysis of these particles show the presence of traces of copper and zinc element. The weight percentage of carbon and oxygen in the blind hole was reduced by $5.86 \%$ and $15.78 \%$ respectively, to accumulate copper and zinc particles of the drill bit. 


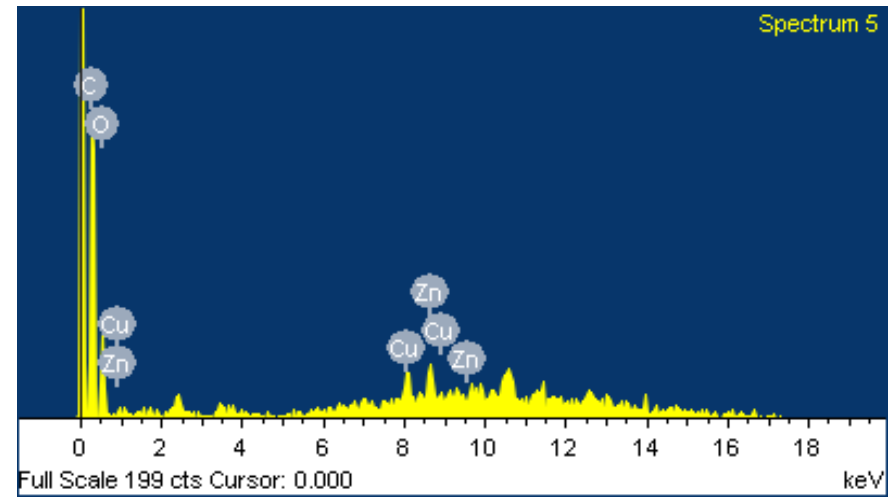

Figure 15: EDS Spectrum of the Blind Hole

\section{CONCLUSION}

Application of domestic microwave applicator has been successfully demonstrated for the process of microwave drilling in PMMA specimen. Copper Litz wire was used to concentrate the heat at drill bit for microwave assisted drilling at $2.45 \mathrm{GHz}, 700 \mathrm{~W}$ parametric setting. The maximum exposure time to obtain blind hole depth of $3 \mathrm{~mm}$ was 3 minute. The simulation results helped to predict the optimized position of the tool and specimen in the microwave applicator.

The possibility of drilling with microwave assistance has been through the experimental and simulation results explored. The other advantages of the process is that no rotary movement was present, thereby reducing the possibility of inaccuracy due to mechanical motion. No special preparation on drill bit was made during these initial trials. Further investigations are needed to fine tune the process in order to obtain required quality although repeatability has been established.

\section{ACKNOWLEDGMENT}

Authors wish to acknowledge the Board of Research in Nuclear Science (BRNS), India, for financial assistance received through DAE Project no. 2010/36/60-BRNS/2048 titled "Material joining and drilling with microwave".

\section{REFERENCES}

[1] E. Jerby and V. Dikhtiar, "Method and Device for Drilling, Cutting, Nailing and Joining Solid Non-conductive Materials using Microwave Radiation", U.S. Patent 6,114,676, 2000.

[2] D. E. Clark and D. C. Folz, "Microwave Solutions for Ceramic Engineers : What Is Microwave Processing?", Journal of American Ceramic Society, Ohio, pp. 1 - 26, 2005.

[3] A. K. Sharma, S. Aravindan and R. Krishnamurthy, "Microwave Glazing of Alumina-titania Ceramic Composite Coatings", Materials Letter, vol. 50, pp. $295-301,2001$.

[4] D. Gupta and A. K. Sharma, "Investigation on Sliding Wear Performance of WC10Co2Ni Cladding Developed through Microwave Irradiation", Wear vol. 271, pp. 1642-1650, 2011.

[5] A. K. Sharma, M. S. Srinath and P. Kumar, "Microwave Joining of Metallic Materials", Indian Patent, Application No. 1994/Del/2009, 2009.

[6] M. S. Srinath, A. K. Sharma and P. Kumar, "A New Approach to Joining of Bulk Copper using Microwave Energy", Materials and Design, vol. 32, pp. 2685 - 2694, 2011.

[7] T. J. George, A. K. Sharma and P. Kumar, "A Feasibility Study on Drilling of Metals through Microwave Heating", i-manager's Journal on Mechanical Engineering, vol. 2, no. 2, pp. 1-6, 2012.
[8] N. K. Lautre, A.K. Sharma, P. Kumar and S. Das, "Performance of different Drill Bits in Microwave Assisted Drilling", International Journal of Mechanical Engineering and Robotics Research, vol. 1, no. 1 , pp. $22-29,2014$.

[9] E. Jerby and V. Dikhtyar, "Drilling into Hard Non-Conductive Materials by Localized Microwave Radiation", 8th International conference on microwave high-frequency heating, Bayreuth, Germany, pp. 687-694, 2001.

[10] E. Jerby, O. Aktushev, V. Dikhtyar, P. Livshits, A. Anaton, T. Yacoby, A. Flax, A. Inberg and D. Armoni, "Microwave Drill Applications for Concrete, Glass and Silicon", 4th World Congress microwave radiofrequency applications, Austin, Texas, pp. 156-165, 2004.

[11] E. Jerby, V. Dikhtyar and O. Aktushev, "Microwave Drill for Ceramics", American Ceramic Society Bulletin, vol. 82, pp. 35-37, 2003.

[12] E. Jerby, V. Dikhtyar and M. Einat, "Microwave Melting and Drilling of Basalt", AIChE annual meeting, Austin, Texas, p. 1673, 2004.

[13] C. Zhang, N. R. Quick and A. Kar, "A Model for Self-defocusing in Laser Drilling of Polymeric Materials", Journal of Applied Physics, vol. 103, no. 014909, pp. 1-8, 2008.

[14] Y. Yang, C. Wang, Z. Qin, L. Xu, Y. Song and H. Chen, "Drilling Force and Temperature of Bone by Surgical Drill", Advanced Materials Research, vol. 126-128, pp. 779- 784, 2010.

[15] M. M. Okasha, P.T. Mativenga, N. Driver and L. Li, "Sequential Laser and Mechanical Micro-Drilling of $\mathrm{Ni}$ Superalloy for Aerospace Application", Manufacturing Technology, vol. 59, pp. 199 - 202, 2010.

[16] H. Fukagawa, T. Hirogaki, T. Kato, A. Kato and M. Seki, "Development of Hole Generation Technology for Aircraft CFRP Parts", Key Engineering Materials, vol. 523-524, pp. 226 - 231, 2012.

[17] A. Sanpanich, K. Petsarb, W. Sroykham, W. Angkhananuwat, C. Phairoh, C. Apaiwong, S. Thanangkul, Y. Kajornpredanon and P. Phasukkit, "An Investigation of Microwave Ablation for Bone Thermal Drilling", IEEE MTT-S International Microwave Conference, pp. 1 - 2, 2013.

[18] C. Phairoh, A. Sanpanich, Y. Kajornpredanon, S. Thanangkul, C. Apaiwong, W. Sroykham, K. Petsarb, P. Phasukkit and K. Roongprasert, "Bone Drilling by using Microwave Ablation: FEM investigation", Biomedical Engineering International Conference, pp. 1 - 5, 2013.

[19] J. A. Abdulnabi, T. A. Tawfiq, A. A. Al-Dergazly, Z. A. Taha and K. I. Hajim, "Precise Hole Drilling in PMMA Using $1064 \mathrm{~nm}$ Diode Laser CNC Machine", Advances in Materials Science and Engineering, vol. 137407, pp. 1-5, 2011.

[20] P. G. Berrie and F. N. Birkett, "The Drilling and Cutting of Polymethyl Methacrylate (Perspex) By $\mathrm{Co}_{2}$ Laser", Optics and Lasers in Engineering, vol. 1, pp. $107-129,1980$.

[21] N. Masmiati and P.K. Philip, "Investigations on Laser Percussion Drilling of Some Thermoplastic Polymers", Journal of Materials Processing Technology, vol. 185, pp. 198 - 203, 2007.

[22] I. A. Choudhury, W. C. Chong and G. Vahid, "Hole Qualities in Laser Trepanning of Polymeric Materials", Optics and Lasers in Engineering, vol. 50, pp. $1297-1305,2012$.

[23] M. D. Shirk and P. A. Molian, "A Review of Ultrashort Pulsed Laser Ablation of Materials", Journal of Laser Applications, 10 (1), 1998, 18 28.

[24] O. Yalukova and I. Sarady, "Investigation of Interaction Mechanisms in Laser Drilling of Thermoplastic and Thermoset Polymers using Different Wavelengths", Composites Science and Technology, vol. 66, pp. $1289-1296,2006$.

[25] S. Lazare, J. Lopez and F. Weisbuch, "High-aspect-ratio Microdrilling in Polymeric Materials with intense $\mathrm{KrF}$ Laser Radiation", Applied Physics, vol. A69, pp. 1-6, 1999.

[26] V. N. Tokarev, J. Lopez, S. Lazare and F. Weisbuch, "High-aspect-ratio Microdrilling of Polymers with UV Laser Ablation: Experiment with Analytical Model", Applied Physics, vol A76, pp. 385 - 396, 2003.

[27] A. Kovacevic, M. Sreckovic, R. Gospavic, S. Ristic and P. Jovanic, "Laser - PMMA Interaction and Mechanical Stresses", ACTA Physica Polonica, vol. A112, pp. 981 - 986, 2007.

[28] C. L. Kang, Y. Xu, K. L. Yung, W. Chen and H. Liu, "Laser Drilling on Elastomeric Polymers", Advanced Materials Research, vol. 591-593, pp. $307-310,2012$.

[29] A. Krishnamoorthy, S. R. Boopathy and K. Palanikumar, "Delamination Prediction in Drilling of CFRP Composites using Artificial Neural Network", Journal of Engineering Science and Technology, vol. 6, no. 2, pp. $191-203,2011$. 
[30] A. Faraz and D. Biermann, "Subsequent Drilling on Pilot Holes in Woven Carbon Fibre Reinforced Plastic Epoxy Laminates: The Effect of Drill Chisel Edge on Delamination", Proceedings of the Institution of Mechanical Engineers, Part B: Journal of Engineering Manufacture, pp. 1493 - 1504, 2011.

[31] S. Arul, L. Vijayaraghavan and S. K. Malhotra, "Online Monitoring of Acoustic Emission for Quality Control in Drilling of Polymeric Composites", Journal of Materials Processing Technology, vol. 185, pp. $184-190,2007$.

[32] K. Pitchai, S. L. Birla, J. Subbiah and D. D. Jones, "Heating Performance Assesment of Domestic Microwave Ovens", International Microwave Power Institute's 44th Annual Symposium, pp. 1-7, 2010.

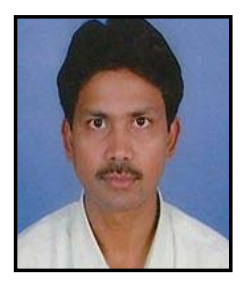

Nitin K. Lautre is working as a Research Scholar in the department of Mechanical and Industrial Engineering, Indian Institute of Technology, Roorkee, India. He obtained his graduate and post-graduate degree in Mechanical and Industrial engineering respectively from Nagpur University. $\mathrm{He}$ has an industrial experience of about 01 year seven month in one of the Bharat Ratna defence company. He has a teaching experience of about 12 years and handled various student projects. He is member of various societies and presented paper in Japan and USA. He has in his credit about 30 conference and six journal papers. His research interest is Non-conventional machining and hybrid machining processes.

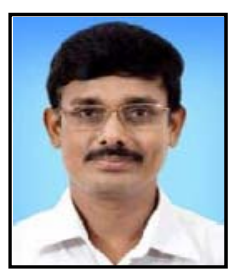

Dr. Apurbba K. Sharma, currently working as Associate Professor in the Department of Mechanical and Industrial Engineering at the Indian Institute of Technology Roorkee, India. He obtained his Bachelor's Degree in Mechanical Engineering from Dibrugarh University and Master's and Doctoral Degrees from Indian Institute of Technology Madras, India. He has guided five Ph.D students and currently supervising six doctoral theses. He has published more than 55 articles in journals and 67 articles in international conferences. He is a reviewer to various international journals. He holds one Indian Patent to his credit and has filed four more recently. Currently, he is Principal Investigator for three externally funded projects.

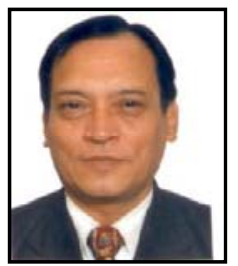

Dr. Pradeep Kumar is working as a Professor in the Department of Mechanical and Industrial Engineering at Indian Institute of Technology Roorkee, (formerly University of Roorkee), India. He earned his BS in Industrial Engineering in 1982, his MS in Production Engineering in 1989 and his PhD in 1994, all from the University of Roorkee, Roorkee, India. He has also served DRF Industries and the Steel Authority of India Ltd as a Production Engineer for four years. His research interests include quality engineering, reliability analysis, product and process design, optimization, non-conventional machining processes, and metal casting. He has published 55 papers in national and international journals and conference proceedings. He has supervised $25 \mathrm{Ph} . \mathrm{D}$ theses, 82 M.Tech dissertations and several Graduate theses. He was honored as outstanding teacher in the year 2005 and 2009. He completed 9 sponsored projects and currently working on 8 research projects. He also holds various administrative post and membership of various esteemed societies. 